\title{
Impact of Cardiorespiratory Fitness on the Obesity Paradox in Heart Failure with Reduced Ejection Fraction
}

\author{
Rita IIhão Moreira, ${ }^{1}$ Tiago Pereira Silva, ${ }^{1}$ António Valentim Gonçalves, ${ }^{1}$ Joana Feliciano, ${ }^{1}$ Pedro Rio, ${ }^{1}$ Rui Soares, ${ }^{1}$ \\ Rui Cruz Ferreira ${ }^{1}$ \\ Hospital de Santa Marta, ${ }^{1}$ Lisboa - Portugal
}

\begin{abstract}
Background: Higher body mass index (BMI) has been associated with improved outcomes in heart failure with reduced ejection fraction. This finding has led to the concept of the obesity paradox.

Objective: To investigate the impact of exercise tolerance and cardiorespiratory capacity on the obesity paradox.

Methods: Outpatients with symptomatic heart failure and left ventricular ejection fraction (LVEF) $\leq 40 \%$, followed up in our center, prospectively underwent baseline comprehensive evaluation including clinical, laboratorial, electrocardiographic, echocardiographic, and cardiopulmonary exercise testing parameters. The study population was divided according to BMI $\left(<25,25-29.9\right.$, and $\left.\geq 30 \mathrm{~kg} / \mathrm{m}^{2}\right)$. All patients were followed for 60 months. The combined endpoint was defined as cardiac death, urgent heart transplantation, or need for mechanical circulatory support. P value $<0.05$ was considered significant.

Results: In the 282 enrolled patients (75\% male, $54 \pm 12$ years, BMI $27 \pm 4 \mathrm{~kg} / \mathrm{m}^{2}$, LVEF $27 \% \pm 7 \%$ ), the composite endpoint occurred in $\mathbf{2 4 . 4 \%}$ during follow-up. Patients with higher BMI were older, and they had higher LVEF and serum sodium levels, as well as lower ventilatory efficiency $\left(\mathrm{VE} / \mathrm{VCO}_{2}\right)$ slope. $\mathrm{VE} / \mathrm{VCO}_{2}$ and peak oxygen consumption $\left(\mathrm{pVO} \mathrm{O}_{2}\right)$ were strong predictors of prognosis $(\mathrm{p}<\mathbf{0 . 0 0 1})$. In univariable Cox regression analysis, higher BMI was associated with better outcomes (HR 0.940, CI $0.886-0.998$, p 0.042). However, after adjusting for either VE/ $\mathrm{VCO}_{2}$ slope or $\mathrm{pVO} \mathrm{2}^{\prime}$ the protective role of BMI disappeared. Survival benefit of BMI was not evident when patients were grouped according to cardiorespiratory fitness class $\left(\mathrm{VE} / \mathrm{VCO}_{2}\right.$, cut-off value 35 , and $\mathrm{pVO}_{2}$, cut-off value $\left.14 \mathrm{~mL} / \mathrm{kg} / \mathrm{min}\right)$.
\end{abstract}

Conclusion: These results suggest that cardiorespiratory fitness outweighs the relationship between BMI and survival in patients with heart failure. (Arq Bras Cardiol. 2020; 115(4):639-645)

Keywords: Heart Failure; Obesity; Body Mass Index; Breathing Exercises; Stroke Volume; Cardiorespiratory Fitness; Respiratory Function Tests.

\section{Introduction}

Obesity impacts most cardiovascular disease risk factors, and it is an independent risk factor for the development of heart failure (HF), being present in approximately $20 \%$ to $30 \%$ of patients with advanced HF. ${ }^{1-3}$ However, multiple investigators have demonstrated that elevated body mass index (BMI) is paradoxically associated with improved clinical outcomes in the setting of established HF, which has been termed the "obesity paradox". ${ }^{4-6}$

Various competing and often contradictory mechanisms have been proposed to explain the HF obesity paradox. Possible reasons include increased levels of serum lipoproteins, ${ }^{7}$ low levels of adiponectin, ${ }^{8}$ and decreased

Mailing Address: Rita Ilhão Moreira •

Hospital Santa Marta - Rua Santa Marta, 50. 1169-024, Lisboa - Portugal E-mail: ritailhaomoreira@gmail.com

Manuscript received June 04, 2019, revised mnauscript July 07, 2019, accepted October 23, 2019

DOI: https://doi.org/10.36660/abc.20190337 response to sympathetic activation. ${ }^{9}$ Confounding factors have also been suggested as a potential explanation. ${ }^{10}$

Cardiorespiratory fitness, measured variously as peak oxygen uptake $\left(\mathrm{pVO}_{2}\right)$ or ventilatory efficiency slope $\left(\mathrm{VE} / \mathrm{VCO}_{2}\right.$ slope), has been identified as an important predictor of survival in HF. ${ }^{11,12}$ A strong obesity paradox has been demonstrated in patients with coronary heart disease, ${ }^{13,14}$ but not in patients with high levels of exercise tolerance. ${ }^{15,16}$

We aim to investigate the impact of exercise tolerance and cardiorespiratory capacity on the obesity paradox.

\section{Methods}

The investigation conforms to the principles outlined in the Declaration of Helsinki. All participants filled out a written informed consent form, and the institutional ethics committee approved the study protocol.

\section{Selection of patients and complementary evaluation}

We performed a prospective cohort study including all patients with HF with reduced ejection fraction (HFrEF) $(\leq 40 \%)$, in New York Heart Association (NYHA) class II or 
III, followed in the Heart Failure Clinics of our institution. All patients referred to the Heart Failure Clinics underwent comprehensive complementary evaluation, from 2000 to 2009. Clinical, laboratorial, electrocardiographic, echocardiographic, and cardiopulmonary exercise test data were prospectively collected; all exams were performed within a period of one month for each patient.

Patients with any of the following factors were excluded: age under 18 years old, planned percutaneous coronary revascularization or cardiac surgery, exerciselimiting comorbidities (including cerebrovascular disease, musculoskeletal impairment, and severe peripheral vascular disease), and previous heart transplant.

A maximal symptom-limited treadmill cardiopulmonary exercise test was performed using the modified Bruce protocol (GE Marquette Series 2000 treadmill). Minute ventilation, oxygen uptake, and carbon dioxide production were obtained breath-by-breath, using a SensorMedics Vmax 229 gas analyzer. Before each test, the equipment was calibrated in standard fashion using reference gases. Patients were encouraged to perform exercise until the respiratory exchange ratio (ratio between carbon dioxide production and oxygen consumption, RER) was $\geq 1.10$. The $\mathrm{pVO}_{2}$ was defined as the highest 30-second average achieved during exercise and was normalized for body mass; surrogate for fat-free mass was considered in obese patients (BMI $\geq 30 \mathrm{~kg} / \mathrm{m}^{2}$ ). Percentage of predicted $\mathrm{pVO}_{2}$ was calculated according to Hansen et $\mathrm{al}^{17}$. The $\mathrm{VE} / \mathrm{VCO}_{2}$ slope was calculated by least squares linear regression, using data acquired throughout the whole exercise $^{18}$. The electrocardiographic data was interpreted by a physician during the exam. Weight and height were obtained, using a 110-CH Welmy anthropometric scale, before the cardiopulmonary exercise test was performed.

A GE Vivid 9 ultrasound system was used to acquire parasternal long- and short-axis views, as well as apical two-, three-, and four-chamber views. Echocardiographic parameters, including left ventricle end-diastolic and end-systolic volumes and left ventricle ejection fraction, were determined according to the American Society of Echocardiography's recommendations.

\section{Follow-up and endpoint}

All patients were followed-up for 60 months. Patients were evaluated for the occurrence of death, heart transplant, or the need for mechanical circulatory support. Data was obtained from the outpatient clinic visits and review of medical charts, with a complementary standardized telephone interview for all patients at 12, 36, and 60 months of follow-up.

The combined endpoint was defined as cardiac death, urgent heart transplant (occurring during unplanned hospitalization due to worsening of HF, requiring inotropes), or need for mechanical circulatory support.

\section{Statistical analysis}

Patients were divided into the following three groups according to BMI: < 25, $25-29.9$, and $\geq 30 \mathrm{~kg} / \mathrm{m}^{2}$. Cardiorespiratory fitness was dichotomized into low- and high-risk according to $\mathrm{VE} / \mathrm{VCO}_{2}$ (cut-off value of $35^{19}$ ) and
$\mathrm{pVO}_{2}$ (cut-off value of $14 \mathrm{~mL} / \mathrm{kg} / \mathrm{min}^{11}$ ). Categorical data are presented as frequencies (percentages), and continuous variables as mean (standard deviation), as appropriate. Continuous variables were analyzed using the unpaired Student's t test after normality was verified (KolmogorovSmirnov test); categorical variables were analyzed using the chi-squared or Fisher's exact tests. One-way analysis of variance (ANOVA) was used for between-group comparison, when appropriate. Univariable and multivariable Cox regression models were applied to analyze time until the combined endpoint. Survival was estimated by Kaplan-Meier analysis and compared by log-rank test. Further analysis of the lower BMI group $\left(<25 \mathrm{~kg} / \mathrm{m}^{2}\right)$ was performed, separating BMI $<20$ and BMI $20-24.9 \mathrm{~kg} / \mathrm{m}^{2}$. However, due to the small percentage of patients with BMI $<20 \mathrm{~kg} / \mathrm{m}^{2}$ (only 17 patients), only baseline characteristics were evaluated (Supplementary Table S1 and Supplementary Figure S1), and no further statistical analysis was performed. All statistical tests were two-sided. $\mathrm{P}$ value $<0.05$ was considered significant. SPSS version 21 software (SPSS Inc., Chicago, Illinois, USA) was used for computation.

\section{Results}

A total of 282 patients were included, with mean age of $53.7 \pm 12.1$ years; $75.5 \%$ were male, with mean BMI 26.8 $\pm 4.3 \mathrm{~kg} / \mathrm{m}^{2}$, and $37.6 \%$ had ischemic cardiomyopathy. Mean left ventricular ejection fraction (LVEF) was $27.4 \% \pm 7.3 \%$, and $23.0 \%$ of patients were in NYHA class $\geq$ III. Regarding therapy, $96.8 \%$ were receiving an angiotensin-converting enzyme inhibitor or angiotensin receptor blocker; $80.1 \%$ were receiving a beta-blocker; $68.1 \%$ were receiving a mineralocorticoid antagonist, and $26.2 \%$ had biventricular pacing. All patients were followed up during 60 months. The combined end point of cardiac death, urgent heart transplant, or need for mechanical circulatory support occurred in $24.4 \%$ of patients.

\section{Body mass index groups}

Baseline characteristics of patients according to BMI groups are shown in Table 1. Patients with higher BMI were older, and they had higher LVEF and serum sodium levels. Exercise effort was, on average, maximal in all BMI groups $($ RER > 1.05), although higher BMI was associated with lower RER value. Elevated BMI was associated with lower $\mathrm{VE} / \mathrm{VCO}_{2}$ slope ( $\mathrm{p}$ 0.005), as well as numerically higher $\mathrm{pVO}_{2}$ and percentage of predicted $\mathrm{pVO}_{2}$, which did not reach statistical significance, however.

In an unadjusted Cox proportional hazards model, BMI was a predictor of event-free survival when expressed as a continuous variable (hazard ratio [HR] 0.940, Cl $0.886-$ 0.998, p 0.042, Table 2) or a dichotomous variable (log-rank $\mathrm{p}$ value 0.047 , Figure 1).

\section{Cardiorespiratory fitness}

Both $\mathrm{VE} / \mathrm{VCO}_{2}$ slope and $\mathrm{pVO}_{2}$ were strong predictors of event-free survival in univariable analysis $(\mathrm{p}<0.001$, Table 2). 
Original Article

Table 1 - Baseline characteristics according to BMI class

\begin{tabular}{|c|c|c|c|c|}
\hline Baseline characteristics & $\begin{array}{c}\mathrm{BMI}<25 \mathrm{~kg} / \mathrm{m}^{2} \\
(\mathrm{n}=99)\end{array}$ & $\begin{array}{c}\text { BMI } 25-29.9 \mathrm{~kg} / \mathrm{m}^{2} \\
(\mathrm{n}=119)\end{array}$ & $\begin{array}{c}\mathrm{BMI} \geq 30 \mathrm{~kg} / \mathrm{m}^{2} \\
\quad(\mathrm{n}=64)\end{array}$ & $\mathrm{p}$ \\
\hline Age, years, mean (SD) & $49.0( \pm 9.6)$ & $59.3( \pm 4.5)$ & $57.3( \pm 8.5)$ & 0.022 \\
\hline Male sex, n (\%) & $70(70.7 \%)$ & $92(77.3 \%)$ & $51(79.7 \%)$ & 0.359 \\
\hline Ischemic etiology, n (\%) & $37(37.4 \%)$ & $44(37.0 \%)$ & $25(39.1 \%)$ & 0.961 \\
\hline Diabetes mellitus, $\mathrm{n}(\%)$ & $8(8.0 \%)$ & $30(25.2 \%)$ & $22(35.1 \%)$ & $<0.001$ \\
\hline LVEF, \% mean (SD) & $24.0( \pm 5.2)$ & $28.3( \pm 0.6)$ & $27.8(3.6)$ & 0.003 \\
\hline NYHA class $\geq I I I, n(\%)$ & $29(29.6 \%)$ & $24(20.3 \%)$ & $12(19.0 \%)$ & 0.184 \\
\hline ACE inhibitors / ARBs, $n(\%)$ & $98(99.0 \%)$ & $113(95.0 \%)$ & $62(96.9 \%)$ & 0.241 \\
\hline Beta-blockers, n (\%) & $75(75.8 \%)$ & $99(83.2 \%)$ & $53(82.8 \%)$ & 0.335 \\
\hline Mineralcorticoid antagonist, n (\%) & $63(63.6 \%)$ & $86(72.3 \%)$ & $44(68.6 \%)$ & 0.364 \\
\hline Biventricular pacing, n (\%) & $21(21.2 \%)$ & $33(27.7 \%)$ & $19(29.7 \%)$ & 0.402 \\
\hline $\mathrm{ICD}, \mathrm{n}(\%)$ & $23(23.2 \%)$ & $30(25.2 \%)$ & $16(35.0 \%$ & 0.938 \\
\hline $\mathrm{Hb}, \mathrm{g} / \mathrm{dL}$ mean $(\mathrm{SD})$ & $15.0( \pm 1.3)$ & $12.4( \pm 1.1)$ & $13.6( \pm 1.7)$ & 0.075 \\
\hline eGFR, mL/min/1.73 m² mean (SD) & $103.4( \pm 48.5)$ & $69.0( \pm 23.3)$ & $73.0( \pm 23.5)$ & 0.140 \\
\hline Sodium, mEq/L mean (SD) & $134.5( \pm 7.1)$ & $139.0( \pm 2.6)$ & $136.4( \pm 4.8)$ & 0.025 \\
\hline BNP, pg/mL mean (SD) & $534.3( \pm 365.3)$ & $350.7( \pm 89.0)$ & $573.4( \pm 300.6)$ & 0.710 \\
\hline RER, mean (SD) & $1.13( \pm 0.14)$ & $1.06( \pm 0.49)$ & $1.07( \pm 0.15)$ & 0.023 \\
\hline $\mathrm{pVO}_{2}, \mathrm{~mL} / \mathrm{kg} / \mathrm{min}$ mean (SD) & $15.0( \pm 2.6)$ & $15.2( \pm 3.9)$ & $16.1( \pm 2.8)$ & 0.758 \\
\hline$\%$ predicted $\mathrm{pVO}_{2}, \%$ mean (SD) & $43.0( \pm 8.4)$ & $55.3( \pm 9.3)$ & $60.3( \pm 16.1)$ & 0.207 \\
\hline VE/VCO ${ }_{2}$ slope, mean (SD) & $43.4( \pm 6.6)$ & $33.8( \pm 6.0)$ & $33.1( \pm 8.1)$ & 0.005 \\
\hline
\end{tabular}

BMI: body mass index; LVEF: left ventricular ejection fraction; NYHA: New York Heart Association; ACE inhibitors: angiotensin-converting enzyme inhibitors; ARB: angiotensin receptor blocker; ICD: implantable cardioverter defibrillator; $\mathrm{Hb}$ : hemoglobin; eGFR: estimated glomerular filtration rate; BNP: brain natriuretic peptide; RER: respiratory exchange ratio; $p \mathrm{VO}_{2}$ peak oxygen consumption; VENCO, slope: ventilator efficiency slope. $P$ calculated by analysis of variance.

Table 2 - Composite endpoint according to unadjusted body mass index and cardiopulmonary exercise test parameters

\begin{tabular}{lcc}
\hline Dependent variable & HR (95\% Cl) & $\mathrm{p}$ \\
\hline $\mathrm{BMI}$, unadjusted & $0.940(0.886-0.998)$ & 0.042 \\
$\mathrm{VE} / \mathrm{VCO}_{2}$ slope, unadjusted & $1.164(1.135-1.194)$ & $<0.001$ \\
$\mathrm{PVO}_{2}$, unadjusted & $0.791(0.742-0.842)$ & $<0.001$ \\
\hline
\end{tabular}

BMI: body mass index; HR: hazard ratio; $V E N \mathrm{NO}_{2}$ slope: ventilator efficiency slope; $\mathrm{PVO}_{2}$ : peak oxygen consumption.

When patients were grouped into low- and high-risk cardiorespiratory fitness classes according to $\mathrm{VE} / \mathrm{VCO}_{2}$ slope, BMI was not a predictor of clinical outcomes on univariate Cox regression analysis ( $\mathrm{p} 0.771$ for $\mathrm{VE} / \mathrm{VCO}_{2}$ slope $>35$ and $\mathrm{p} 0.439$ for $\mathrm{VE} / \mathrm{VCO}_{2}$ slope $\leq 35$ ). Figure 2 illustrates the event-free survival characteristics of each cardiorespiratory fitness group. Furthermore, BMI did not affect event-free survival when patients were grouped for $\mathrm{pVO}_{2}\left(\mathrm{p} 0.170\right.$ for $\mathrm{pVO}_{2} \leq 14 \mathrm{~mL} / \mathrm{kg} / \mathrm{min}$ and $\mathrm{p} 0.164$ for $\left.\mathrm{pVO}_{2}>14 \mathrm{~mL} / \mathrm{kg} / \mathrm{min}\right)^{2}$.

Although BMI was a predictor of prognosis on univariable analysis, after using a Cox regression analysis adjusting for VE/ $\mathrm{VCO}_{2}$ slope, BMI lost its prognostic capacity (p 0.786, Table 3). Moreover, there was no relationship between BMI and event-free survival after adjusting for $\mathrm{pVO}_{2}$ (p 0.201, Table 3).

\section{Discussion}

In this study, we evaluated whether cardiorespiratory capacity affects the obesity paradox. The findings can be summarized as follows: (1) obesity paradox is present in this HF population; (2) VE/VCO slope and $\mathrm{pVO}_{2}$ are strong prognostic predictors, and (3) most importantly, the prognostic capacity of BMI is lost when considering either of these two cardiorespiratory fitness parameters.

Obesity is a major risk factor for the development of HF. In the Framingham Heart Study, with 5,881 participants, the risk of HF doubled in obese subjects (HR 1.90 for men and HR 2.12 for women). ${ }^{20}$ These results were similar in larger studies, including one with over 59,000 participants free of HF at baseline, where the multivariable-adjusted HRs for developing 


\section{Original Article}

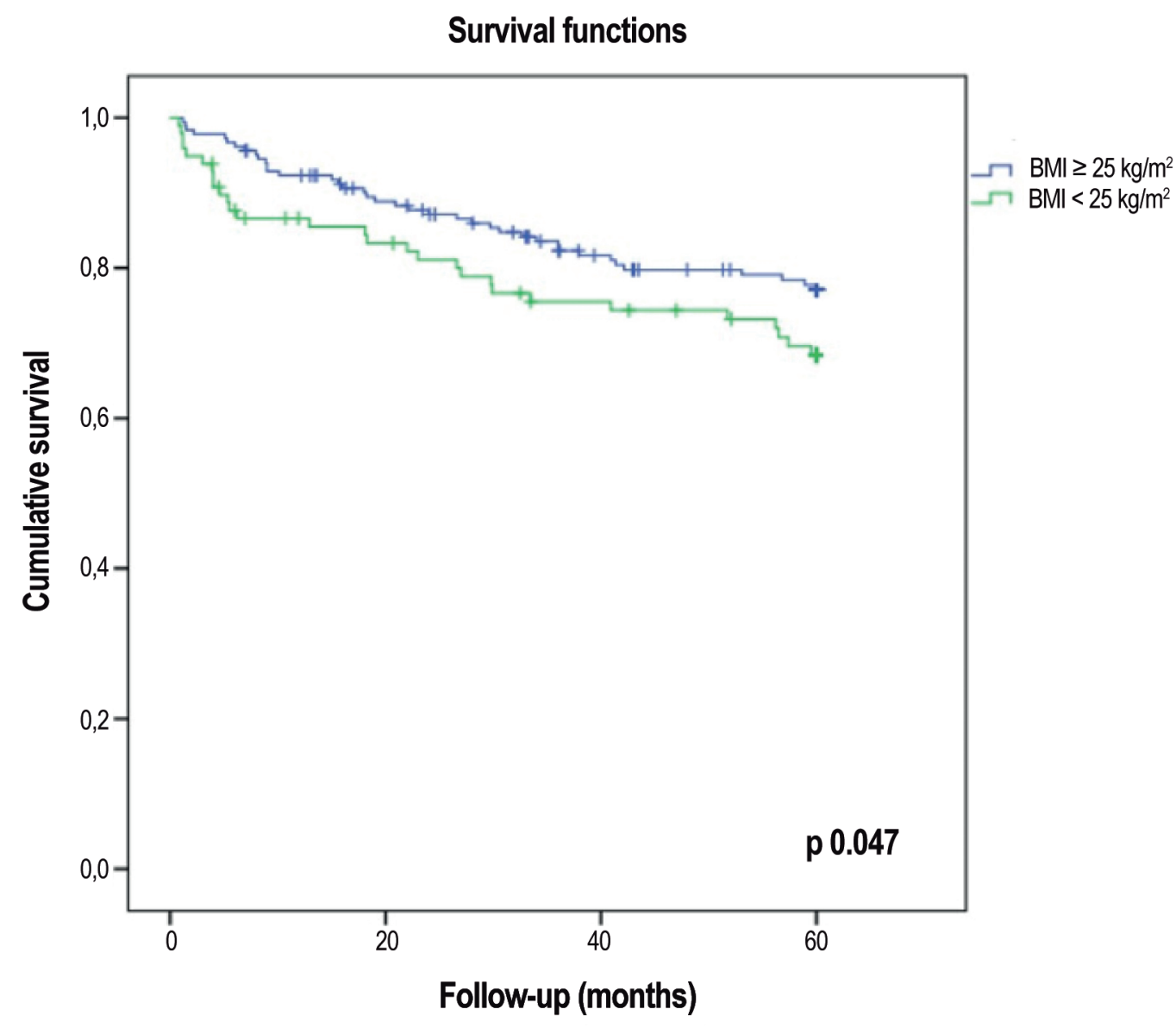

Figure 1 - Kaplan-Meier analysis according to body mass index (BMI) in the overall group.
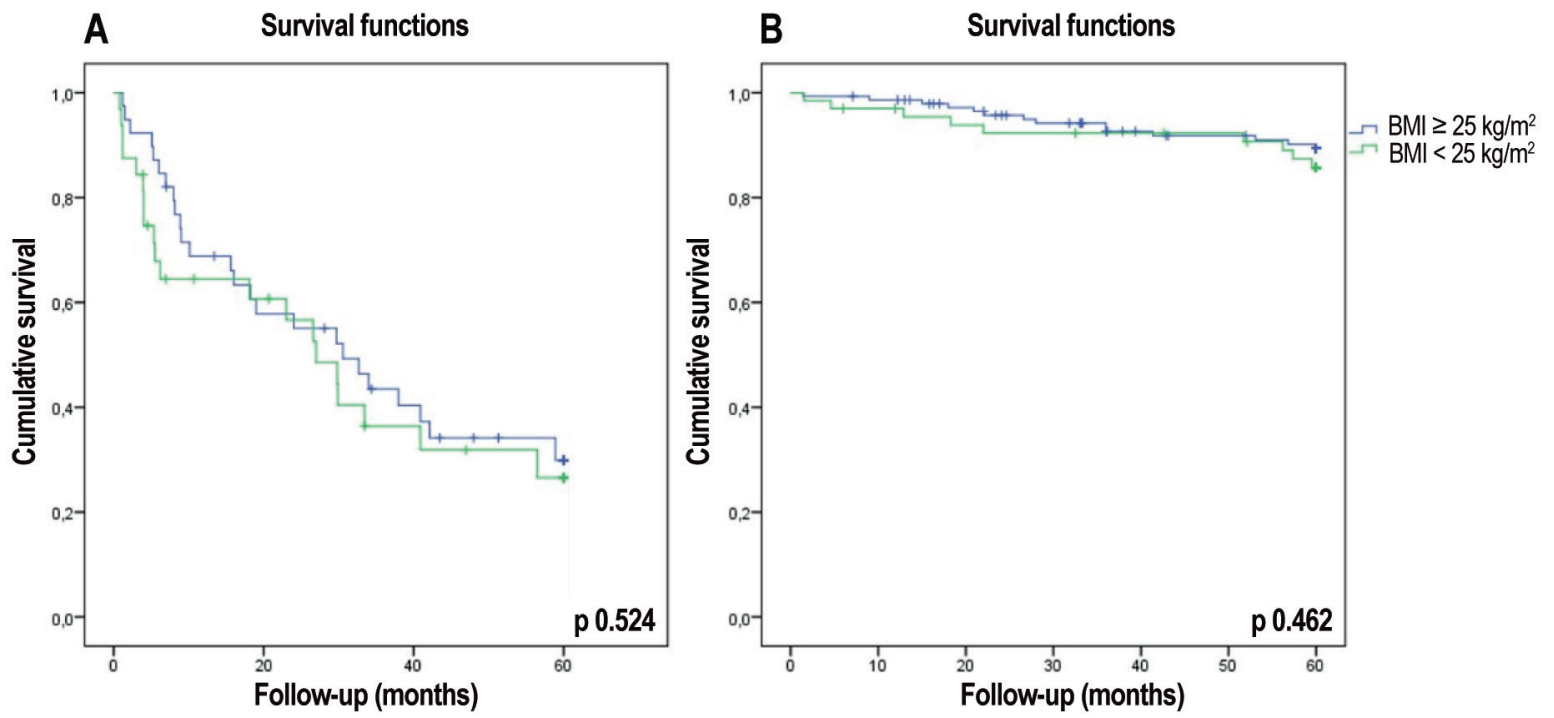

Figure 2 - Kaplan-Meier analysis according to body mass index (BMI) in the (A) low cardiorespiratory fitness group (VENCO, slope > 35) and (B) high cardiorespiratory fitness group (VENCO, slope $\leq 35)$. 
Table 3 - Composite endpoint according to body mass index adjusted to cardiopulmonary exercise test parameters.

\begin{tabular}{lcc}
\hline Dependent variable & HR $(95 \%$ Cl) & p \\
\hline BMI, adjusted by $\mathrm{VE} / \mathrm{VCO}_{2}$ & $1.008(0.949-1.072)$ & 0.786 \\
\hline $\mathrm{BMI}$, adjusted by $\mathrm{pVO}_{2}$, & $0.949(0.892-1.020)$ & 0.201 \\
\hline
\end{tabular}

BMI: body mass index; HR: hazard ratio; VENCO ${ }_{2}$ slope: ventilator efficiency slope; $\mathrm{pVO}_{2}$ peak oxygen consumption.

$\mathrm{HF}$ at different levels of $\mathrm{BMI}(<25,25-29.9$, and $\geq 30 \mathrm{~kg} /$ $\mathrm{m}^{2}$ ) were $1.00,1.25$, and 1.99 for men and 1.00, 1.33, and 2.06 for women, respectively. ${ }^{21}$

Although elevated BMI constitutes an independent risk factor for $\mathrm{HF}$, multiple investigations have shown a reverse association between BMI and mortality, leading to the concept of "obesity paradox." One of the first studies in 2001, with 1,203 patients with advanced HFrEF, showed that BMI > 27.8 $\mathrm{kg} / \mathrm{m}^{2}$ was associated with a statistically significant survival benefit. ${ }^{5}$ An analysis of in-hospital survival and BMI in more than 100,000 patients with decompensated HF identified that mortality risk was lowered by $10 \%$ for every 5 -unit increase in $\mathrm{BMI}{ }^{22}$ Furthermore, a meta-analysis including $>22,000$ patients with chronic HF showed that the risk of cardiovascular mortality and hospitalization was lowest in overweight patients (relative risk 0.79 and 0.92 compared to normal BMI, respectively). ${ }^{23}$ In our cohort of patients with $\mathrm{HF}$, patients with higher BMI also presented better prognosis (Figure 1).

Historically, $\mathrm{pVO}_{2}$ has been the cardiorespiratory exercise test variable most widely used for determining HF prognosis and timing of transplant. ${ }^{11}$ However, other variables, including $\mathrm{VE} / \mathrm{VCO}_{2}$ slope, are also strong predictors of prognosis. ${ }^{19}$ The additional advantage of VE/VCO slope measurement is that its value is still reliable if a patient does not reach a maximal effort (RER > 1.05) and therefore does not achieve his or her "true" $\mathrm{pVO}_{2}{ }^{24}$

In our study, $\mathrm{VE} / \mathrm{VCO}_{2}$ slope and $\mathrm{pVO}_{2}$ were both strong predictors of prognosis. Chase et al. ${ }^{12}$ demonstrated that VE/ $\mathrm{VCO}_{2}$ slope maintains prognostic value irrespective of BMI in patients with $\mathrm{HF}^{12}$. We also demonstrated that higher BMI conveys a better outcome in unadjusted analysis. However, when either $\mathrm{VE} / \mathrm{VCO}_{2}$ slope or $\mathrm{pVO}_{2}$ were considered, BMI lost its prognostic capacity. Moreover, when the patients were grouped according to their cardiorespiratory fitness class, BMI did not influence outcomes. Analyzing our HF population by BMI class, we were also able to observe that patients with higher BMI had better prognostic parameters (including LVEF, sodium levels, and VE/VCO, slope), indicating that these patients presented a less advanced HF condition.

These findings indicate that the obesity paradox might be mitigated and even negated by cardiorespiratory fitness, and it may only represent a survival or index event bias. $\mathrm{HF}$ is a catabolic state, and elevated BMI may represent metabolic reserve, while lower BMI may be a consequence of unintentional weight loss and cardiac cachexia, which is associated with poor prognosis. ${ }^{25}$ Additionally, the clinical experience in our Heart Failure Clinics has shown that obese patients may experience greater functional impairment due to increased body mass and therefore seek medical assistance first, leading to earlier implementation of prognostic therapy.
Additionally, it is possible that some of the patients identified as "obese," in fact, have increased muscle mass and muscular strength. ${ }^{26}$

The obesity paradox has previously been challenged in other studies. Lavie et al. ${ }^{16}$ demonstrated that, in patients with HFrEF, BMI was a significant predictor of survival in the group with low cardiorespiratory fitness $\left(\mathrm{pVO}_{2}<14 \mathrm{~mL} / \mathrm{kg}\right.$ ) $\mathrm{m}^{2}$ ), but not in the high cardiorespiratory fitness group. ${ }^{16}$ More recently, Piepoli et al. ${ }^{27}$ verified that the prognostic role of BMI disappeared when age, gender, LVEF, and $\mathrm{pVO}_{2}$ were taken into consideration. ${ }^{27}$

These previous studies that evaluated the influence of cardiorespiratory fitness on the obesity paradox only analyzed the influence of $\mathrm{pVO}_{2}$, which is effort-dependent and highly influenced by patient motivation. ${ }^{28}$ In our study, we also demonstrated that $\mathrm{VE} / \mathrm{VCO}_{2}$ slope, which is a maximal effort-independent parameter, mitigated the obesity paradox. Therefore, the relationship between cardiorespiratory fitness and the obesity paradox is not influenced by maximal exercise effort performed during the test.

Despite the benefit of weight loss in the prevention of adverse cardiac remodeling, HF, and other cardiac diseases, there is no clear consensus regarding weight loss in patients with HF. Large clinical trials are needed to better understand the benefits and risks of weight reduction in patients with HF. Given the current state of evidence, it may be reasonable to advise purposeful weight loss, particularly in those with more severe degrees of obesity, incorporating the benefits of physical activity, exercise training, and cardiorespiratory fitness. ${ }^{29,30}$

\section{Limitations}

This is a single center study, which limits the generalization of results. Nevertheless, this made it possible for the cardiorespiratory exercise test protocol to be homogeneous in all cases, and it may have reduced the number of physicians responsible for interpretation of the exam, thus reducing interobserver variability. Additionally, the population comprised patients with HFrEF (mean systolic LVEF $27.4 \% \pm 7.3 \%$ ) who were able to perform exercise and, therefore, the results may not apply to the entire HF population. A further limitation is that patients with higher BMI presented lower RER. However, these patients had the highest exercise performance, and analysis with $\mathrm{VE} / \mathrm{VCO}_{2}$ slope overcomes this limitation, as it is a maximal effort-independent parameter.

\section{Conclusion}

In the studied HF population, BMI was not related to outcomes when cardiorespiratory exercise test variables 


\section{Original Article}

were taken into consideration. Therefore, cardiorespiratory fitness affects the relationship between BMI and survival in HF patients.

\section{Author contributions}

Conception and design of the research and Statistical analysis: Moreira RI; Acquisition of data: Moreira RI, Silva TP, Gonçalves AV, Feliciano J, Rio P; Analysis and interpretation of the data: Moreira RI, Gonçalves AV; Writing of the manuscript: Moreira RI, Silva TP; Critical revision of the manuscript for intellectual content: Soares $\mathrm{R}$, Ferreira RC.

\section{References}

1. Loehr LR, Rosamond WD, Poole C, Mcneill AM, Chang PP, Folsom AR, et al. Association of multiple anthropometrics of overweight and obesity with incident heart failure: The atherosclerosis risk in communities study. Circ Hear Fail 2009;2(1):18-24.

2. Djoussé L, Bartz TM, IxJH, Zieman SJ, DelaneyJA, Mukamal KJ, et al. Adiposity and incident heart failure in older adults: the cardiovascular health study. Obesity (Silver Spring) 2012;20(9):1936-41

3. Bozkurt B, Aguilar D, Deswal A, Dunbar SB, Francis GS, Horwich T, et al. Contributory risk and management of comorbidities of hypertension, obesity, diabetes mellitus, hyperlipidemia, and metabolic syndrome in chronic heart failure: A scientific statement from the American Heart Association. Circulation. 2016;134(23):535-78.

4. Oreopoulos A, Padwal R, Kalantar-Zadeh K, Fonarow GC, Norris CM, McAlister FA. Body mass index and mortality in heart failure: A meta-analysis. Am Heart J. 2008; 156(1):13-22.

5. Horwich TB, Fonarow GC, Hamilton Ma, MacLellan WR, Woo Ma, Tillisch JH. The relationship between obesity and mortality in patients with heart failure. J Am Coll Cardiol. 2001;38(3):789-95.

6. Clark AL, Fonarow GC, Horwich TB. Waist circumference, body mass index, and survival in systolic heart failure: The obesity paradox revisited. J Card Fail $.2011 ; 17(5): 374-80$.

7. Rauchhaus M, Clark AL, Doehner W, Davos C, Bolger A, Sharma R, et al. The relationship between cholesterol and survival in patients with chronic heart failure. J Am Coll Cardiol. 2003;42(11):1933-40.

8. Mohamed-Ali V, Goodrick S, Bulmer K, Holly JMP, Yudkin JS, Coppack SW. Production of soluble tumor necrosis factor receptors by human subcutaneous adipose tissue in vivo. Am J Physiol - Endocrinol Metab. 1999;277(6):E971-5.

9. Weber MA, Neutel JM, Smith DHG. Contrasting clinical properties and exercise responses in obese and lean hypertensive patients. J Am Coll Cardiol. 2001;37(1):169-74.

10. Ades PA, Savage PD. The obesity paradox: Perception vs knowledge. Mayo Clinic Proc. 2010;85(2):112-4.

11. Mancini DM, Eisen H, Kussmaul W, Mull R, Edmonds LH, Wilson JR. Value of peak exercise oxygen consumption for optimal timing of cardiac transplantation in ambulatory patients with heart failure. Circulation. 1991;83(3):778-86.

12. Chase P, Arena R, Myers J, Abella J, Peberdy MA, Guazzi M, et al. Relation of the prognostic value of ventilatory efficiency to body mass index in patients with heart failure. Am J Cardiol. 2008;101(3):348-52.

13. Romero-Corral A, Montori VM, Somers VK, Korinek J, Thomas RJ, Allison TG, et al. Association of bodyweight with total mortality and with cardiovascular events in coronary artery disease: a systematic review of cohort studies. Lancet. 2006; 368(9536):666-78.

\section{Potential Conflict of Interest}

No potential conflict of interest relevant to this article was reported.

\section{Sources of Funding}

There were no external funding sources for this study.

\section{Study Association}

This study is not associated with any thesis or dissertation work.

14. Lavie CJ, De Schutter A, Patel DA, Romero-Corral A, Artham SM, Milani $\mathrm{R} \mathrm{V}$. Body composition and survival in stable coronary heart disease: Impact of lean mass index and body fat in the "obesity paradox." J Am Coll Cardiol. 2012;60(15):1374-80.

15. McAuley PA, Kokkinos PF, Oliveira RB, Emerson BT, Myers JN. Obesity paradox and cardiorespiratory fitness in 12,417 male veterans aged 40 to 70 years. Mayo Clin Proc. 2010;85(2):115-21.

16. Lavie CJ, Alpert MA, Arena R, Mehra MR, Milani R V., Ventura HO. Impact of obesity and the obesity paradox on prevalence and prognosis in heart failure. JACC Heart Fail. 2013;1(2):93-102.

17. Hansen J, Sue D, Wasserman K. Predicted values for clinical exercise testing. Am Rev Respir Dis. 1984;129(2P2):S49-55.

18. Guazzi M, Adams V, Conraads V, Halle M, Mezzani A, Vanhees $\mathrm{L}$, et al. Clinical recommendations for cardiopulmonary exercise testing data assessment in specific patient populations. Circulation. 2012;126(18):2261-74.

19. Chua TP, Ponikowski P, Harrington D, Anker SD, Webb-Peploe K, Clark $\mathrm{L}$, et al. Clinical correlates and prognostic significance of the ventilatory response to exercise in chronic heart failure. J Am Coll Cardiol. 1997;29(7):1585-90.

20. Kenchaiah S, Evans JC, Levy D, Wilson PW, Benjamin EJ, Larson MG, et al. Obesity and the risk of heart failure. N Engl J Med. 2002;347(5):30513.

21. Hu G, Jousilahti P, Antikainen R, Katzmarzyk P. Joint effects of physical activity, body mass index, waist circumference, and waist-to-hip ratio on the risk of heart failure. Circulation. 2010;121(2):237-44.

22. Fonarow GC, Srikanthan P, Costanzo MR, Cintron GB, Lopatin M, ADHERE Scientific Advisory Committee and Investigators. An obesity paradox in acute heart failure: analysis of body mass index and inhospital mortality for 108,927 patients in the Acute Decompensated Heart Failure National Registry. Am Heart J. 2007;153(6):74-81.

23. Sharma A, Lavie CJ, Borer JS, Vallakati A, Goel S, Lopez-Jimenez F, et al. Meta-Analysis of the relation of body mass index to all-cause and cardiovascular mortality and hospitalization in patients with chronic heart failure. Am J Cardiol. 2015;115(10):1428-34.

24. Gitt AK, Wasserman K, Kilkowski C, Kleemann T, Kilkowski A, Bangert $M$, et al. Exercise anaerobic threshold and ventilatory efficiency identify heart failure patients for high risk of early death. Circulation. 2002;106(24):3079-84.

25. Anker SD, Negassa A, Coats AJ, Afzal R, Poole-Wilson PA, Cohn JN, et al. Prognostic importance of weight loss in chronic heart failure and the effect of treatment with angiotensin-converting-enzyme inhibitors: An observational study. Lancet 2003;361(9363):1077-83. 
26. Oreopoulos A, Kalantar-Zadeh K, McAlister F, Ezekowitz J, Fonarow $\mathrm{G}$, Johnson J et al. Comparison of direct body composition assessment methods in patients with chronic heart failure. J Card Fail. 2010;16(11):867-872.

27. Piepoli MF, Corrà U, Veglia F, Bonomi A, Salvioni E, Cattadori G, et al. Exercise tolerance can explain the obesity paradox in patients with systolic heart failure: Data from the MECKI Score Research Group. Eur J Heart Fail. 2016;18(5):545-53.
28. Ramos-Barbón D, Fitchett D, Gibbons WJ, Latter DA, Levy RD. Maxima exercise testing for the selection of heart transplantation candidates: Limitation of peak oxygen consumption. Chest. 1999;115(2):410-7.

29. Lavie CJ, Alpert MA, Ventura HO. Risks and Benefits of Weight Loss in Heart Failure. Heart Fail Clin. 2015;11(1):125-31.

30. Kunutsor S, Laukkanen J. Heart failure risk reduction: is fit and overweight or obese better than unfit and normal weight? Eur J Heart Fail. 2019;21(4):445-8. 